\title{
Applying Problem based learning in the Sports Science Curriculum
}

\author{
By Maria Konstantaki ${ }^{*}$
}

Objectives: The aim of this study was to investigate the effectiveness of problem based learning (PBL) in improving the student learning experience in sports science. $P B L$ is an innovative method of learning within experiential learning that has been used extensively in other disciplines, but its use within sports science is limited. Method: Twenty five undergraduate students (20 male, 5 female) in their second year of study of the BSc (Hons) in Sports Science and Coaching Studies (mean $\pm S D$ age: $20.1 \pm 4.0$ y) were recruited to the study. All students attended the study module entitled 'Sports Injuries' that was delivered in a three hour weekly block (one hour lecture, two hours laboratory practical). The PBL intervention lasted 12 weeks. In the classroom, at the end of each lecture, the students watched a video recording of a taping or strapping technique for a specific sports injury and took notes. In the laboratory, students formed small groups of three (one practitioner, one patient, one observer) and performed the taping procedures using their notes, recollection of the video and with minimal guidance from the lecturer. The lecturer only provided feedback upon completion of the procedure. At the end of the study period, students were asked to complete a ten-item questionnaire expressing their views on PBL, its effectiveness, its advantages/disadvantages, its benefits to assessed work, the lack of lecturer involvement and their enjoyment of the module. Results: Students commented that PBL was a 'fun way to learn', 'it gave freedom to interact with peers', 'it helped to improve concentration, critical thinking as well as practical skills'. On the other hand, it was suggested that it would be beneficial for some less confident students if the lecturer gave a demonstration of the procedure in the beginning of the practical class. Discussion: Findings showed overwhelming student support of $P B L$ as an alternative method of teaching and learning in sports science. With $P B L$ the lecturer facilitates rather than dictates the learning process which is beneficial for the students' journey towards independent learning.

\section{Introduction}

Learning concerns the way in which we perceive and understand the world; it is about establishing meaning (Marton and Booth, 1997). Learning may involve mastering abstract principles, remembering factual information, understanding methods, techniques and approaches and debating ideas (Fry et al., 2003). Experience gained through education and work plays a central role in the process of learning and this perspective on learning is called

${ }^{*}$ Senior Lecturer in Sports Science, Department of Sports Management, Buckinghamshire New University. 
'experiential learning' or 'learning by doing'. Experiential learning is based on the notion that understanding is not a fixed or unchangeable element of thought, but it is formed and re-formed through 'experience'. It is also a continuous process, often represented as cyclical, and, being based on experience, implies that we all bring to learning situations our own ideas and beliefs at different levels of elaboration (Fry et al., 2003). Probably the most popular theory of learning from experience can be attributed to Kolb (1984), who developed ideas from other models of experiential learning. The cyclical model of learning that has become known as the 'Kolb Learning Cycle' requires four kinds of abilities / undertaking, if learning is to be successful (Diagram 1).

Diagram 1. The 'Kolb Learning Cycle'. From Fry et al. (2003)

Concrete Experience (CE)

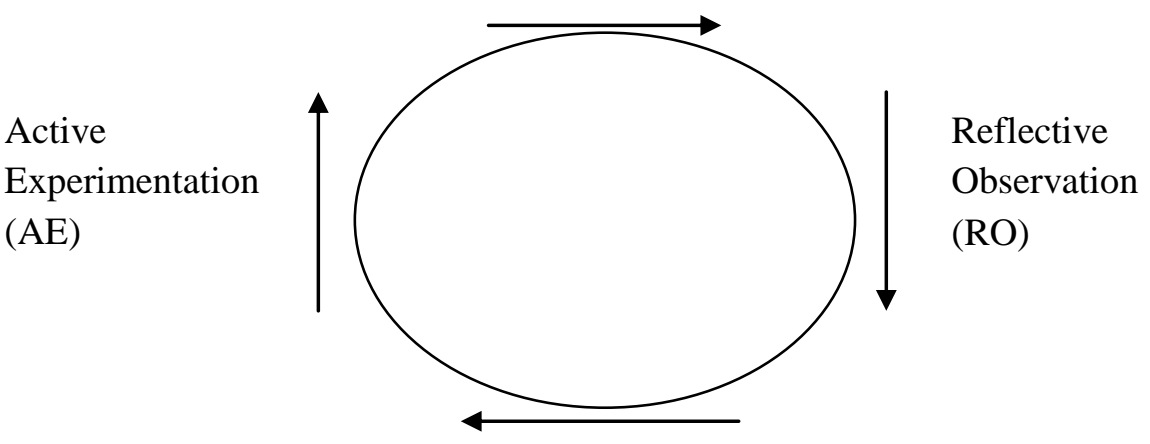

Abstract

Conceptualisation

(AC)

Kolb's (1984) learning cycle suggests that, in order to learn effectively from experience, there must be a movement through reflection on experience where observations on the features and issues in the context are brought to conscious attention. There follows a focus on generalising from experiences and understanding them. This part of the cycle is where theories and ideas are brought to bear on the experience. In the third part of the cycle there is an attempt to evaluate the experience and to plan for change through experimentation. The fourth step takes the learner back into the experience, but this time the experience is informed by the learning cycle (Beaty 2003). The 'experiential learning cycle' does not simply involve doing, but also reflecting, processing, thinking and furthering understanding. One method to engage students in the stages of the learning cycle is problem based learning.

\section{Problem based Learning (PBL)}

Problem based learning (PBL) is perhaps the most innovative instructional method conceived in the history of education (Hung et al., 2008). It is an approach to learning that is characterised by flexibility and diversity in the sense that it can be implemented in a variety of ways in and across different 
subjects and disciplines in diverse contexts (Savin-Baden, 2000). PBL was originally designed to respond to the criticism that traditional teaching and learning methods fail to prepare medical students for solving problems in clinical settings. Instead of requiring that students study content knowledge and then practice context-free problems, PBL embeds students' learning processes in real-life problems (Hung et al., 2008). Wood (2003) reinforces this view by stating that, in the medical sciences, PBL is used to help students define their own learning objectives through using "triggers" from the problem case or scenario. Subsequently they do independent, self-directed study before returning to the group to discuss and refine their acquired knowledge. Thus, PBL is not about problem solving per se, but rather it uses appropriate problems to increase knowledge and understanding (Wood, 2003).

PBL derives from a theory which suggests that for effective acquisition of knowledge, learners need to be stimulated to restructure information they already know within a realistic context, to gain new knowledge, and to then elaborate on the new information they have learned, for example by teaching it to peers or by discussing the material in a group setting (Kilroy, 2004). This theory is termed "information processing approach to learning" and was initially described in 1977 (Anderson, 1977). PBL has been mainly used in the medical sciences to increase student autonomy and it has recently migrated to other areas of learning such as higher education and K12 education (Hung et al., 2008). Within higher education there has been an increase in the use of PBL in a range of subject areas including engineering, architecture, law, business and management, and social work (Savin-Baden, 2003).

In sports science, which is one of the emerging areas of study within higher education, the use of PBL has been limited. According to literature search, there have been two studies that have used PBL in sports science and sports studies programmes, respectively. Martin et al., (2008) investigated the impact of a 12-week problem-based learning (PBL) intervention with 25 sports science final year students on three psychological constructs (motivation, locus of control and self-esteem) linked to learner autonomy. Results indicated that there was a significant increase in the students' intrinsic motivation and a nonsignificant shift towards an internal locus of control after the intervention period. Students perceived the benefits of PBL to be the opportunity to work in teams and to consider a wider knowledge base. A short course of PBL was successful in developing learner autonomy and other key employability skills alongside the application of content knowledge (Martin et al., 2008).

Duncan and Al-Nakeeb (2006) noted that even though PBL has been widely used to develop students' critical thinking, interaction and problem solving skills, few authors have documented how problem-based learning has been integrated into undergraduate sports related courses. They investigated the effectiveness of PBL with sports studies students and they published a paper on the process of developing an undergraduate module in Sports Studies using PBL. In their paper they provide recommendations on suitable methods of assessment while incorporating student views on PBL compared to more 
traditional undergraduate module delivery. These workers reported that, for students, the use of a PBL approach appears to offer advantages in terms of student enjoyment, engagement and development of criticality compared to traditional lecture-led delivery in Sports Studies. However, care may need to be taken in terms of timescale for delivery, particularly with groups who have no experience of PBL.

With such limited application of PBL within sports science, there is a lot of scope for research. The purpose of the present study was to explore the effectiveness of PBL on improving the student learning experience within a sport science module.

\section{Method}

\section{Participants}

A purposive sample of second year undergraduate students $(n=25$; male $=20$, female $=5$; mean \pm SD age: $20 \pm 4$ y) studying for a BSc (Hons) in Sports Science and Coaching Studies at Buckinghamshire New University was used for the purposes of this research study. The students were all members of a cohort attending a module entitled Sports Injuries. This module was delivered for three hours every week over a period of 15 weeks. This delivery period included 12 weeks of teaching followed by two weeks of assessment (a 20-min practical exam incorporating knowledge of theory) and one week to provide feedback on assessed work. The three hour block was arranged to include a one-hour classroom-based lecture and two hours practical session in the Human Performance/Physiology laboratory. The PBL intervention period lasted 12 weeks. The study gained Ethical approval by the ethics committee at Buckinghamshire New University.

\section{PBL Approach}

At the end of each lecture, the students watched a video recording of a taping or strapping technique for a specific sports injury and took detailed notes. The recording was repeated as many times as it was needed for students to complete their notes. Students were encouraged to create 'mind maps' or diagrams as they saw fit in order to help their understanding of the taping/strapping technique procedure. Following this, the group moved to the Human Performance Laboratory. In the laboratory, students were instructed to form small groups of three (one practitioner, one patient, one observer) and to perform the selected taping/strapping procedure using their notes and recollection of the video recording. The lecturer was simply observing the groups and circulated around the laboratory without offering guidance until the procedure was completed. There was a general discussion at the end of the laboratory class where students interacted with the lecturer and pointed out areas for clarification and improvement of the technique they performed.

\section{Questionnaire Design}

The design of the survey questionnaire was based on the steps proposed by Morrow et al., (2005) for conducting survey research. First, the objectives of the research were determined (i.e. purpose identified and variables to be 
observed were listed). Second, the type of sampling and sample size were identified. Third, the questionnaire was constructed to include questions relevant to the topic of investigation. Fourth, a pilot study with a small number of students was carried out in order to identify and define the themes that were used in the survey. Finally, the questionnaire was administered to the study population, the results were analysed and suitable conclusions were drawn. The type of questionnaire used in this study was a self-administered questionnaire.

\section{Data Collection and Analysis}

At the end of the study period, students were asked to complete a ten-item questionnaire expressing their views on PBL and its effectiveness as a teaching and learning method. The items included a closed-ended ('yes' or 'no' answers) and open-ended questions to allow students to express their views, comments and make suggestions (Morrow et al., 2005). The items included questions on PBL advantages and disadvantages, PBL benefits to student assessed work, student views on lack of lecturer involvement in the PBL process and student enjoyment of the PBL approach and the module itself. Students were also asked to comment on the concept of PBL, the skills they felt they developed through using it and their experience of working in groups.

Data was analysed using two methods. First, the closed-ended responses were analysed for percentages and frequencies using Excel version 13.0. Second, thematic analysis was employed to analyse statements and sentences from the open-ended questions and clustered them into common themes as described by Biddle et al., (2001). The frequency count of each theme was calculated to identify its importance compared to other themes in the same thematic group. Higher frequency themes were selected as representative of the thematic group.

\section{Results}

\section{Quantitative Results}

The results of the closed-ended item analysis showed that student responses were positive in their overwhelming majority. Ninety three per cent of students agreed that PBL fosters active participation, whereas 95\% agreed that it enhanced their understanding of module content. Eighty seven per cent of students agreed that PBL encourages deep learning experiences and 67\% were positive that PBL helped them develop vocational skills such as team work, communication and critical thinking. Figure 1 shows the students' responses in terms of \% agreement (positive response) and disagreement (negative response) with the questionnaire items on PBL. 
Figure 1. PBL Effectiveness shown as a Percentage of Positive and Negative Responses to the Items in the Survey Questionnaire

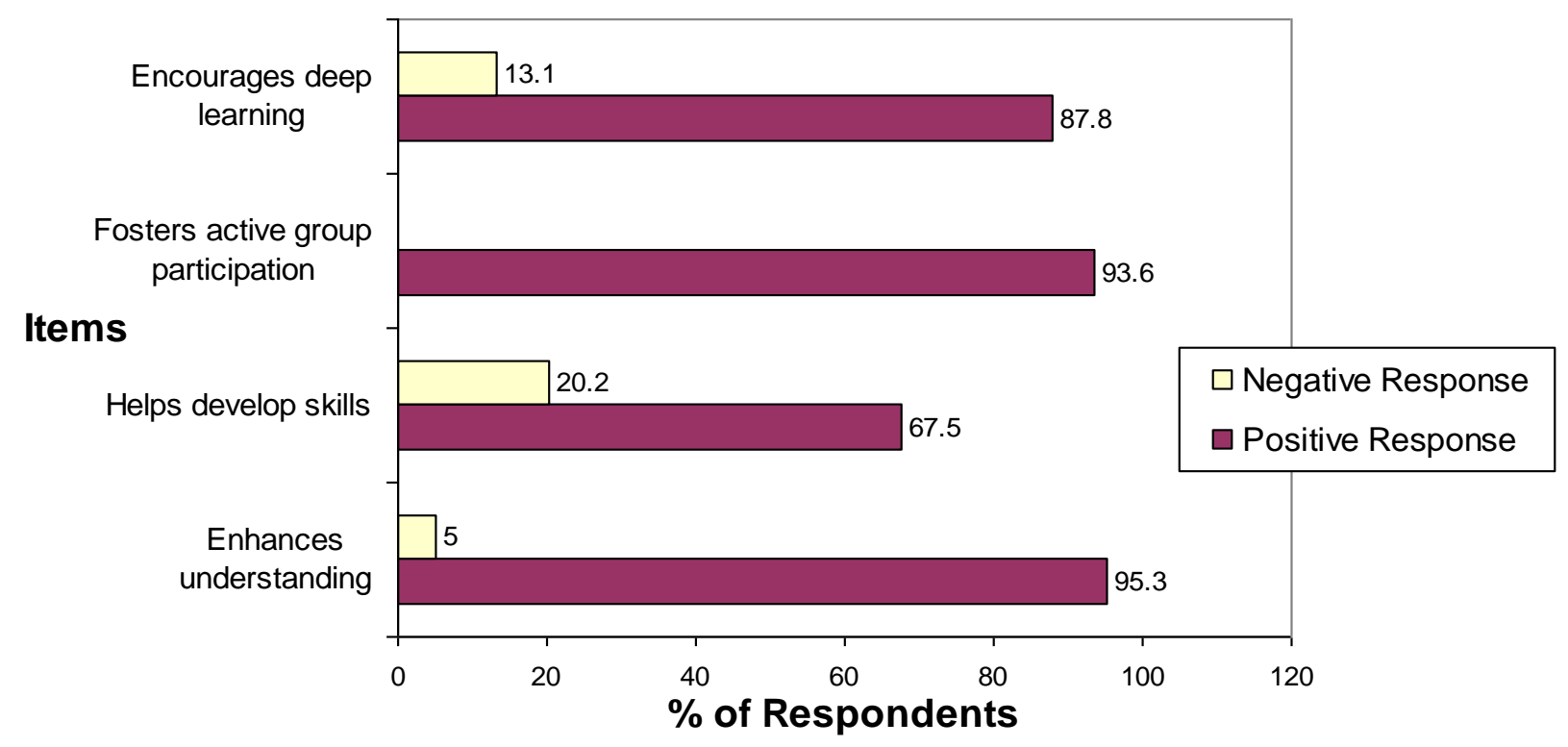

Eighty point five per cent of students agreed that PBL contributed to increasing their enjoyment of the study module, whereas $67.4 \%$ perceived the PBL mode of delivery as motivation to attend classes. Sixty point two per cent of students agreed that PBL had a positive effect on their assessed work i.e. it helped them perform better in the practical assessment. Finally, the majority of students $(60.8 \%)$ agreed that they did not wish the lecturer to be involved in the practical sessions in a leading role however, $27.7 \%$ stated that they would like some lecturer involvement. These results are shown in Figure 2.

Figure 2. PBL Impact on Attendance, Assessment and Module Effectiveness

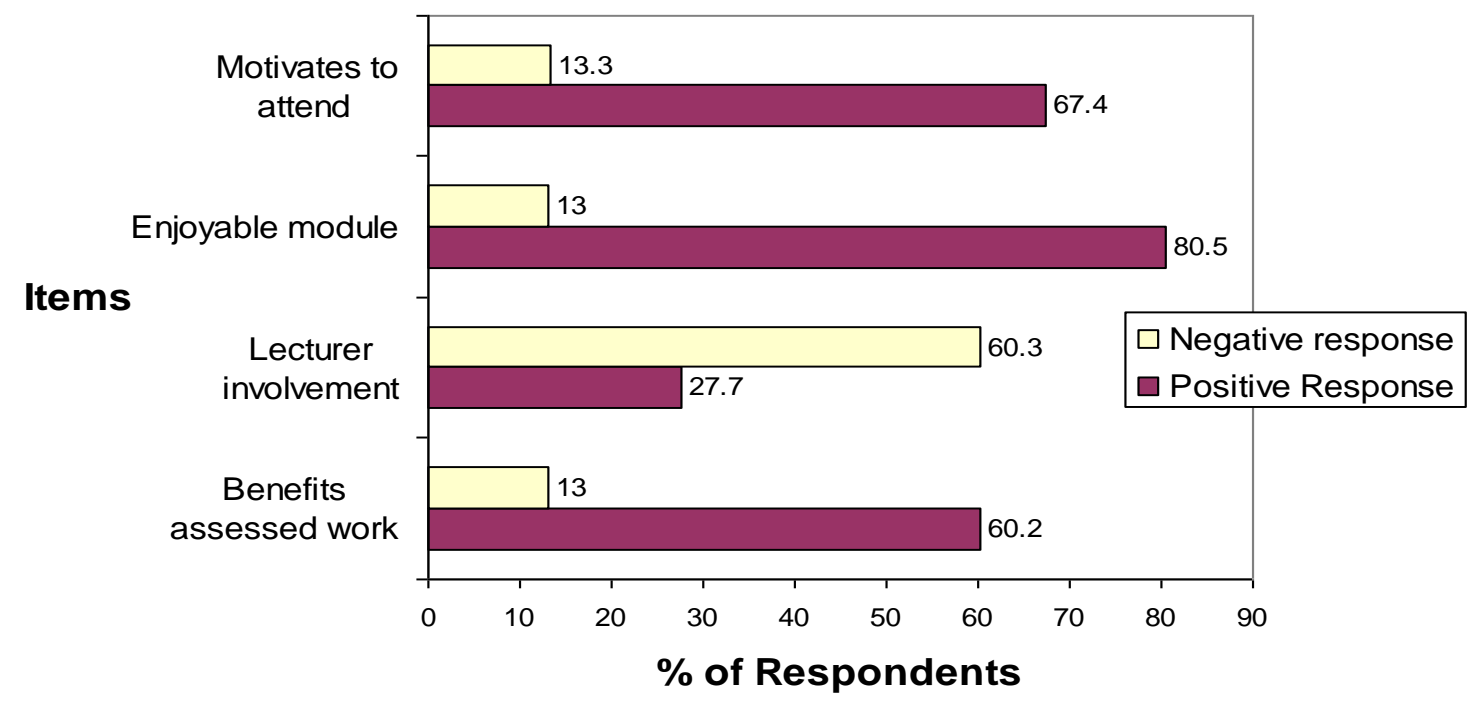

Qualitative Results

Thematic analysis revealed positive and negative student views on the use of PBL within the Sports Injuries module with the majority of views indicating 
a positive response to the intervention. The student comments are summarised in Diagram 1.

Diagram 1. Student Views on PBL; Positive and Negative Quotes

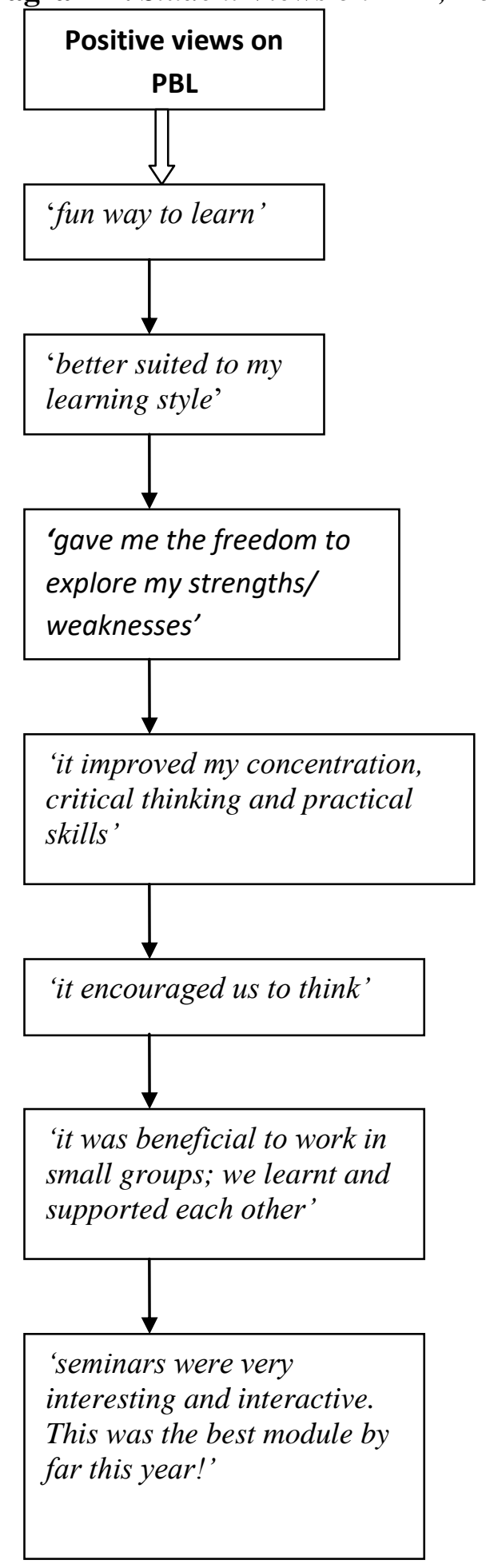

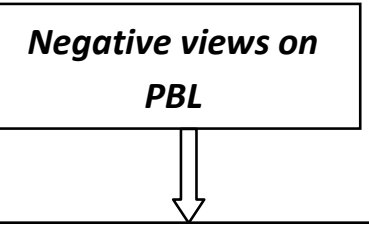

I would like the lecturer to give a demonstration at the beginning; not all of us are confident working from memory or our notes'

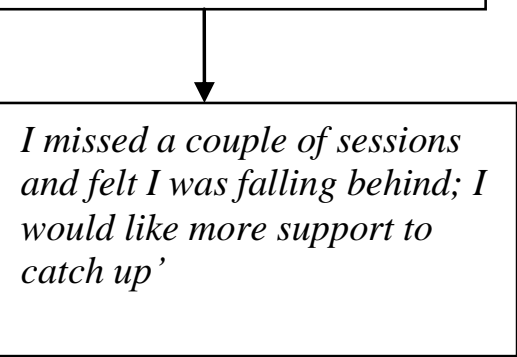




\section{Discussion}

The findings of this study showed overwhelming student support of PBL as an alternative method of teaching and learning and engaging students with the sports science curriculum. Student support was evident by their degree of agreement with enhancing their learning experience and the positive quotes they have used to describe their experience of PBL. Previously, Kilroy (2004) who conducted PBL with training of clinical staff suggested that by providing a more stimulating learning environment for junior staff, PBL can help make them more satisfied and more confident in their clinical role. There were few students who perceived the PBL approach in a slightly negative way. These results agree with those stated previously by Duncan and Al-Nakeeb (2006). Parallel to our study, the students in Duncan and Al-Nakeeb's study had not experienced the type of delivery involved with PBL previously but although many found this a challenge to begin with, the delivery of the module was perceived to be more enjoyable and effective.

Students in the present study commented on PBL as being 'more suited to their personal learning style' and that 'it developed their critical thinking skills and concentration'. Similar results were noted in the study by Martin et al., (2008) who reported that the apparent use of traditional pedagogic learning styles is reducing students' ability to become autonomous by focusing on outcome rather than process. Martin et al., (2008) added that PBL appears to be an effective learning and teaching strategy for sport and exercise science students in higher education, leading to the development of learner autonomy, content knowledge and employability skills. In Duncan's and Al-Nakeeb's (2006) study the students noted that the delivery seemed more relaxed, or casual, compared to traditionally delivered modules.

Another notable finding in this study was that a large number of students described their experience of PBL as 'a fun way to learn' and coined the Sports Injuries module as 'the best module by far!' where 'the seminars were interactive' and 'group work was beneficial'. These results are echoed by Wood (2003) who stated that PBL is fun for students and tutors, and the process requires all students to be engaged in the learning process for a successful learning experience to occur. Hung et al., (2008) also suggested that the quality of PBL problems affects not only various aspects of student learning but also academic achievement. In the current study, students agreed that PBL had a positive impact on their assessed work meaning that it helped them achieve better grades. Similar results were suggested by Camp (1996) who noted that courses employing a PBL approach enable students to construct knowledge based on their prior understanding and enable them to make comparisons with their peers' knowledge, refining their understanding as they gain experience in dealing with the problems they confront.

According to the findings of this study, one area that needs addressing within the PBL approach is cultivating the confidence of the participants. Some students reported that the lecturer needed to provide a demonstration in the 
beginning of the PBL session. However, it has been suggested previously that the effectiveness of problems determines the effectiveness of PBL curriculum (Hung et al., 2008). In our study, the majority of students voted against lecturer involvement. This finding coincides with the view stated by Kilroy (2004) where PBL differs radically from traditional teaching styles in that it centres on " "problem first" learning, rather than the more usual "subject first" way using scenarios to illustrate previously taught material. The leader of a PBL programme acts as a facilitator rather than a teacher, using their expertise not primarily to transmit facts, but to provide encouragement and guidance as the participants tackle the problems they have identified (Kilroy, 2004). The skill of PBL facilitation is that of knowing when to provide assistance to the group be it suggesting useful resources they might like to consider or interjecting with thought provoking comments to guide the breadth and depth of learning, without necessarily imparting facts (Maudsley, 1999). Therefore, the majority of the students in this study were satisfied with the amount of lecturer's involvement in the PBL sessions.

\section{Conclusion}

The application of PBL into the sport and exercise science curriculum is an effective means to motivate the students to engage with the module content and enjoy a rich learning experience. The findings of this study on PBL effectiveness support those of previous studies in the medical sciences and in sports science. The majority of students feel more confident to carry out tasks and become more autonomous in their learning while acquiring valuable employability skills such as critical thinking, problem solving and team work. The motivation of students to attend the sessions was also increased with the PBL approach. The only points to address were those of the least confident students who might need more guidance in the process and the issue of students having missed a class that need extra support to catch up with the material. Last but not least, students enjoy the lack of lecturer involvement and the student-centred approach of PBL.

\section{References}

Anderson, R.C. (1977). The notion of schemata and the educational enterprise: general discussion of the conference. In: Anderson RC, Spiro RJ, Montague WE, (eds). Schooling and the acquisition of knowledge. Hillsdale, NJ: Erlbaum.

Beaty, L. (2003). Supporting learning from experience. In: Fry, H., Ketteridge, S., Marshall, S. (eds.). A handbook for teaching and learning in Higher Education: enhancing academic practice. Kogan Page Ltd., pp. 134-138.

Biddle, S., Markland, D., Gilbourne, D., Chatzissarantis, N., Sparkes, A. (2001). Research methods in sport and exercise psychology: quantitative and qualitative issues. Journal of Sports Sciences, 19, 777-809. 
Camp, G. (1996) Problem-based learning: A paradigm shift or a passing fad? Medical Education 1 (1), 2-6.

Duncan, M. J., Al-Nakeeb, Y. (2006). Using problem based learning in sports related courses: An overview of module development and student responses in an undergraduate Sports Studies module. Journal of Hospitality, Leisure, Sport and Tourism Education, 5(1), 50-57.

Marton, F., Booth, S. (1997). Learning and Awareness. Lawrence Erlbaum Associates, Mahwah, New Jersey.

Maudsley, G. (1999). Roles and responsibilities of the problem-based learning tutor in the undergraduate medical curriculum. British Medical Journal, 318:657-61.

Fry, H., Ketteridge, S., Marshall, S. (2003). A Handbook for Teaching and Learning in Higher Education: Enhancing Academic Practice. $2^{\text {nd }}$ Edition. Kogan Page, London and Sterling, VA.

Hung, W., Jonassen, D. H., Liu, R. (2008). Problem-based learning. Handbook of research on educational communications and technology, 3, 485-506.

Kilroy, D.A. (2004). Problem based learning. Emergency Medicine Journal, 21(4), 411-413.

Kolb, D.A. (1984). Experiential Learning. Prentice-Hall, Englewood Cliffs, New Jersey.

Martin, L., West, J., Bill, K. (2008). Incorporating problem-based learning strategies to develop learner autonomy and employability skills in sports science undergraduates. Journal of Hospitality, Leisure, Sport \& Tourism Education, 7(1), 18-30.

Morrow, J.R., Jackson, A.W., Disch, J.G., Mood, D.P. (2005). Measurement and evaluation in human performance. $3^{\text {rd }}$ edition. Champaign, IL: Human Kinetics.

Savin-Baden, M. (2000) Understanding and using problem-based learning strategically in higher education. Paper presented to the 8th Improving Students Learning Symposium, 4-6 September, UMIST, Manchester.

Savin-Baden, M. (2003) Facilitating problem-based learning. Buckingham: SRHE/Open University Press.

Wood, D. F. (2003). Problem based learning. British Medical Journal, 326(7384), 328-330. 